\title{
Vaccination against tuberculosis, polio and hepatitis B at birth in Podor health district, Northern Senegal: cross-sectional study of vaccination coverage and its associated factors
}

Oumar Bassoum ${ }^{1,2 *}$, Ndeye Mareme Sougou ${ }^{1,2}$, Mouhamadou Faly Ba², Malick Anne ${ }^{3}$, Mamoudou Bocoum³, Alioune Dieye ${ }^{4}$, Cheikh Sokhna ${ }^{5,6}$ and Anta Tal-Dia ${ }^{1,2}$

\begin{abstract}
Background: In Senegal, studies focusing specifically on vaccination coverage with the Bacille de Calmette et Guérin (BCG) vaccine, the birth dose of oral polio vaccine (OPV zero dose) and the birth dose of hepatitis B (HepB-BD) vaccine are insufficient. This study aimed to highlight vaccination coverages with birth doses and factors associated with timely vaccination in Podor health district.

Methods: A cross-sectional study was carried out from June 19 to 22, 2020. The study population consisted of children aged 12 to 23 months of which 832 were included. A stratified two-stage cluster survey was carried out. The sources of data were home-based records (HBR), health facility registries (HFR) and parental recalls. Timely vaccination refers to any vaccination that has taken place within $24 \mathrm{~h}$ after birth. Descriptive analyzes, the chi-square test and logistic regression were performed.

Results: The crude vaccination coverages with BCG, OPV zero dose and HepB-BD were 95.2\%, 88.3\% and 88.1\%, respectively. Vaccination coverages within $24 \mathrm{~h}$ after birth were estimated at $13.9 \%, 30 \%$ and $42.1 \%$, respectively. The factors associated with timely HepB-BD are delivery in a health facility ( $A O R=1.55 ; 95 \% \mathrm{Cl}=1.02-2.40)$, access to television $(A O R=1.63 ; 95 \% C l=1.16-2.29)$, weighing $(A O R=3.92 ; 95 \% C l=1.97-8.53)$ and hospitalization of the newborn immediately after birth $(\mathrm{AOR}=0.42 ; 95 \% \mathrm{Cl}=0.28-0.62)$.
\end{abstract}

Conclusion: Timely administration of birth doses is a challenge in the Podor health district. The solutions would be improving geographic access to health facilities, involving community health workers, raising awareness and integrating health services.

Keywords: Vaccination Coverage, Timely, Birth Doses, Senegal

*Correspondence: oumar.bassoum@ucad.edu.sn

${ }^{1}$ Service de Médecine Préventive Et de Santé Publique, Faculté de Médecine, de Pharmacie Et d'Odontologie (FMPO), Université Cheikh Anta Diop (UCAD), Dakar, Sénégal

Full list of author information is available at the end of the article

\begin{abstract}
Introduction
Vaccination is a preventive act whose objective is to allow the vaccinated individual to benefit from specific protection against an infectious agent before any exposure to it [1]. It is recognized that apart from clean water and sanitation, vaccination has made the greatest contribution to
\end{abstract}


global health, especially in developing countries [2]. Its principle is based on the induction of long-lasting and effective protection against a pathogen responsible for an infectious disease without causing clinical symptoms or side effects [3].

In 1974, the World Health Organization (WHO) established the Expanded Programme on Immunization (EPI). WHO recommends that the Bacille de Calmette et Guérin vaccine, the birth dose of oral polio vaccine (OPVzero dose) and the birth dose of hepatitis B (HepB-BD) vaccine be given at birth, ideally within $24 \mathrm{~h}$ after birth [4-6]. These recommendations are motivated by the heavy burden of tuberculosis, hepatitis B and polio. According to the Global tuberculosis report, published in October 2020, around 10 million people contracted tuberculosis during the year 2019. The number of deaths was 1.4 million [7]. The African Region is one of the most affected regions and is home to $25 \%$ of new cases [7].

According to the Global Hepatitis Report published in 2017, 257 million people were living with chronic hepatitis B in 2015, a prevalence of $3.5 \%$ [8]. A recent mathematical modeling, published in 2018, showed that the number of people with hepatitis B was 291,992,000 in 2016; which corresponds to a prevalence of 3.9\% [9]. Much of the disease-related morbidity results from transmission during childbirth or during infancy. Progression to chronic hepatitis is more common when infection occurs in these circumstances [6].

According to WHO, 10 to 20 million people of all ages are living with paralytic polio [10]. However, five of WHO's six regions, including Africa, are declared free of wild poliovirus and global polio eradication is approaching [11]. To date, transmission of wild poliovirus continues in only two countries, Pakistan and Afghanistan [12].

By 2030, the WHO estimates that vaccine coverage with BCG and HepB-BD followed by subsequent doses of hepatitis B vaccine reaching $90 \%$ should prevent $84 \%$ of hepatitis B virus-related deaths [6] and 115,000 tuberculosis-related deaths per birth cohort during the first 15 years of life [4]. Administration of OPV-zero at birth strongly contributes to the improvement of seroconversion rates after administration of subsequent doses [5, 13].

A Systematic Review and Meta-Analysis showed that in sub-Saharan Africa the pooled coverage rates at day $0-1$ after birth were $14.2 \%$ (95\% CI: 10.1-18.9) for BCG and $1.3 \%(0.0-4.5)$ for HepB-BD. No data were available for OPV0 at day $0-1$. The rates of vaccine coverage immediately after birth were very low for BCG and HepB-BD, and no data for OPV0 [14]. This can be explained by several factors. Of these, human resource factors e.g., staff shortages, lack of training opportunities, poor attitude and gaps in knowledge among healthcare staff are frequently associated with poor uptake of immunization programs in Africa [15]. For population factors, effective vaccination outcomes are not only dependent on accessibility, which remains a major challenge in Africa, but also on the acceptance and willingness of the population to be vaccinated [16]. Thus, one of the major obstacles to achieving high immunisation coverage is vaccine hesitancy [17], which is defined by the World Health Organization (WHO) as delayed acceptance or refusal of vaccination despite the availability of immunisation services [18].

In Senegal, the tuberculosis incidence rate is estimated at 117 cases per 100,000 inhabitants in 2019. Children aged 0 to 14 years old accounted for $4 \%$ of the tuberculosis cases detected in the country [19].

Regarding hepatitis B, Senegal belongs to the group of countries with high endemicity [20]. It has been established that $85 \%$ of the general population have at least one HBV marker [21]. The prevalence in the Senegalese general population is estimated at $11 \%$ [22].

Senegal has implemented the EPI since 1979. In accordance with WHO recommendations, the country has a vaccination policy against tuberculosis, hepatitis $\mathrm{B}$ and polio at birth. The HepB-BD has been integrated into the EPI since February 2016 [23]. However, administration of this dose at birth faces many constraints such as home births and cold chain failures and, in some subSaharan Africa countries, lack of funding [24].

According to the continuous demographic and health survey carried out in Senegal in 2019 (CDHS-2019), vaccination coverage with BCG, OPV-zero dose and HepBBD were respectively $94.5 \%, 80.5 \%$ and $81.3 \%$. In the northern zone to which Podor health district belongs, these indicators are respectively estimated at 93.9\%, 75.3\% and 75.5\% [25]. Administrative data in Podor health district indicate vaccination coverage with BCG and HepB-BD reaching respectively $98 \%$ and $51 \%$ in 2019 [26]. However, these data have shortcomings. The first concerns the CDHS-2019, the results of which do not clearly indicate vaccination coverage within $24 \mathrm{~h}$ after birth. The second shortcoming relates to administrative coverage data which estimate vaccination coverage with an imprecise denominator. This denominator corresponds to the number of children of eligible age, that is, an estimate of the target population for vaccination which can be obtained from a census [27]. Finally, both CDHS-2019 and administrative data did not assess factors that may influence vaccination coverage at birth.

It is in this context that this study was undertaken to help fill these gaps. The purpose is to allow the development of guidance notes in terms of strategies for improving vaccination coverage at birth. The objective of this study was to highlight vaccination coverages with birth 
doses and factors associated with timely vaccination in Podor health district.

\section{Conceptual framework}

Vaccination at birth is linked to access and use of health services. Several studies use Andersen RM theoretical model to understand the factors that condition these events [28]. This present study fits into this logic in order to understand the factors that are associated with the timely administration of the birth dose vaccines. Thus, on the basis of a review of the literature, variables were identified and classified into three categories as recommended by this theoretical model (Fig. 1). Predisposing factors relate to socio-demographic and biological factors in Fig. 1. enabling factors refer to the financial and organizational resources available to individuals to access health services as shown in Fig. 1. Finally, the need factors are those that increase the use of services as shown in Fig. 1.

\section{Study setting}

The study took place in Podor health district, which belongs to the eponymous department and Saint Louis region. The health district is located in northern Senegal, in the middle valley of the Senegal River and about $490 \mathrm{~km}$ from the Senegalese capital, Dakar. It is bounded to the north by the Islamic Republic of Mauritania, to the south by the health districts of Dahra and Linguère which appear to Louga region, to the west by the health district of Dagana and to the east by the health district of Pété. The health district hosts 247,891 inhabitants. The density is estimated at 35 inhabitants per $\mathrm{km}^{2}$ [29]. Much of the region's economic activity relies on agriculture and livestock [30].

It has been established that $45 \%$ of the population is in a mobile or advanced zone, that is to say more than $5 \mathrm{~km}$ from a health facility [29]. The district is home to a hospital, two health centers, one of which is nonfunctional, and thirty-eight health posts [29]. The health district is marked by a deficit in ambulances and motorcycles [29]. Immunization services are offered through three strategies. First, the fixed strategy is practiced at the level of health facilities and concerns the target population living within a radius of $5 \mathrm{~km}$. Second, the advanced strategy is carried out at the level of health huts and sites by the staff of the health facilities. It is aimed at the population of localities located between 5 and $15 \mathrm{~km}$ from a health facility. Third, the mobile strategy targets the population living beyond $15 \mathrm{~km}$ from a health facility [23].

\begin{tabular}{|c|c|c|}
\hline $\begin{array}{l}\text { Predisposing factors } \\
\text { 1. Age of mother } \\
\text { 2. Mother's education } \\
\text { 3. Marital status } \\
\text { 4. Father's profession } \\
\text { 5. Child's sex } \\
\text { 6. Birth order } \\
\text { 7. Knowledge about the age } \\
\text { for beginning vaccination } \\
\text { 8. Knowledge about the } \\
\text { benefits of vaccination } \\
\text { 9. Knowledge about the } \\
\text { fact that several vaccines } \\
\text { could be co-administered } \\
\text { the same day }\end{array}$ & $\begin{array}{l}\text { Enabling factors } \\
\text { 1. Place of residence } \\
\text { 2. Distance from health facility } \\
\text { 3. Access to television } \\
\text { 4. Access to radio } \\
\text { 5. Access to newspaper } \\
\text { 6. Decision-making power } \\
\text { 7. Means of transport } \\
\text { 8. Family allowance } \\
\text { 9. Health insurance } \\
\text { 10. Wealth quintile } \\
\text { 11. Availability of the HBR } \\
\text { 12. Timely initiation of BF } \\
\text { 13. Place of delivery } \\
\text { 14. Year of birth } \\
\text { 15. Season of birth }\end{array}$ & $\begin{array}{l}\text { Need factors } \\
\text { 1. Antenatal care (ANC) } \\
\text { attendance } \\
\text { 2. Advice on vaccination } \\
\text { during ANC } \\
\text { 3. Hospitalization of the } \\
\text { newborn immediately } \\
\text { after birth } \\
\text { 4. Newborn weighing } \\
\text { 5. Gestational age } \\
\text { 6. Type of delivery } \\
\text { 7. Post-natal care (PNC) } \\
\text { attendance } \\
\text { 8. Advice on vaccination } \\
\text { during PNC }\end{array}$ \\
\hline \multicolumn{3}{|c|}{$\begin{array}{l}\text { Utilization of vaccination services } \\
\text { Birth doses vaccination coverage }\end{array}$} \\
\hline
\end{tabular}




\section{Methodology}

\section{Type, period and study population}

It was a cross-sectional study. Data collection took place from June 19 to 22,2020 . The study population consists of children aged 12 to 23 months. This choice is based on the recommendations of the $\mathrm{WHO}$, which considers that the assessment of routine immunization coverage should relate to an annual birth cohort. Children aged 12 to 23 months are the ideal population for estimating recommended dose coverage between 0 and 11 months. This period concerns not only the three birth doses but also other basic antigens, the last of which is given at 9 months, namely the measles-rubella and yellow fever vaccines. Another advantage is the possibility of estimating the full immunization coverage with this study population [31].

\section{Sampling \\ Eligibility criteria}

The eligibility criteria are:

- Being 12 to 23 months old at the time of the survey;

- Having slept in the household the previous night.

\section{Sample size}

The sample size is estimated according to the new WHO recommendations [31].

First, the effective sample size (ESS) is calculated as follows:

$$
n \geq \frac{k z_{1-\frac{\alpha}{2}}^{2}}{4 d^{2}}+\frac{1}{d}-2 z_{1-\alpha / 2}^{2}+\frac{z_{1-\alpha / 2}+2}{k}
$$

- $\mathrm{Z}_{1-\alpha}$ : standard normal distribution evaluated at $1-\alpha=5 \%$

- d: desired half-width of the set confidence interval $=5 \%$

- p: expected vaccination coverage rate $=90 \%$

- $\mathrm{k}=0.51$. WHO estimates that when the expected immunization coverage rate is between 0.7 and $1-\mathrm{d}, \mathrm{k}$ is calculated using the following formula: $\mathrm{k}=4(\mathrm{p}-\mathrm{d})$ $(1-\mathrm{p}+\mathrm{d})=0.51$.

Thus, the ESS is equal to 216 children aged 12 to 23 months. It corresponds to the number of subjects necessary for a simple random survey.

This size will be increased due to the variability between the clusters. To do this, it will be multiplied by a factor called the design effect (DEFF).

$\mathrm{DEFF}=1+(\mathrm{m}-1) \mathrm{X}$ ICC.

- m: number of subjects per cluster equal to 10 .

- ICC: intra-cluster correlation coefficient fixed here at $1 / 3$.
$\mathrm{DEFF}=1+(10-1) \mathrm{X} 0.333=4$.

Thus, the minimum sample size $=$ ESS $\times$ DEFF $=864$. This number is rounded to 870 .

\section{Number of clusters}

The number of clusters to select is calculated by relating the sample size to the number of children required for each cluster.

$$
\frac{870}{10}=87
$$

Then, a distribution proportional to the size was made to determine the number of clusters required for each health structure.

\section{Sampling procedure}

A two-stage cluster sampling was carried out. The survey was stratified according the health facilities. This means that sampling was carried out in each stratum independently. All 39 health facilities were included and each corresponds to a geographical area covering several villages. The first stage corresponds to villages and / or neighborhoods (primary units), the number of which is allocated proportionately according to the size of the geographical area in terms of number of inhabitants. The selection was made according to a simple random survey using the ALEA function of the Excel software. The second stage is made up of households (secondary units). In each village or neighborhood included, households are visited. The first included household is randomly selected from the center of the cluster. Beforehand, a street near the centre of the cluster is drawn at random. The survey started with the first household on the right. The subsequent households are recruited step by step until the required number of children per cluster is reached.

A household may not be included due to unavailability or refusal to participate. In this case, it is replaced by the next household. In accordance with the principle of the cluster survey, all eligible children in a household are included.

\section{Data Collect Survey tool}

The survey tool was a structured questionnaire designed on the basis of the literature [31, 32]. Its validation followed several procedures. First, the research team reviewed and commented on it. Then, a pre-test was carried out in three districts of Podor. The collected Open Data Kit (ODK) application downloaded to smartphone tablets (Android) served as the data collection medium. The entered forms are sent to a server. An internet connection is required for downloading the application and submitting forms, but not for collecting in the field. 
The pre-test is carried out on 80 children aged 12 to 23 months living in three parts of Podor city for purposes of inducing interviewers to become familiar with the survey tools. The comments resulting from the pre-test made it possible to finalize the questionnaire which has five sections: i) socio-demographic characteristics of the parents, ii) individual characteristics of the child, obstetric characteristics, iii) knowledge about vaccination, iv) vaccination data according to the home-based records (HBR) or the health facility registry (HFR) and v) vaccination data from vaccination history as recalled by the child's mothers/caregivers.

\section{Training of interviewers}

Twenty-five interviewers were recruited. They were all students. They were given a two-day training course. The first was devoted to the presentation of the target diseases of the EPI, the vaccination schedule, HBR and the HFR. The second day was dedicated to the presentation of the survey objectives, the questionnaire administration method and the collection tools. A round table was made to read the questions. A question-and-answer game followed to further clarify the concepts. Next, the ODK collect application was presented. The teaching techniques used were PowerPoint presentation and role playing.

\section{Collection method}

Data collection began after verifying that the child belonged to the age group concerned by the survey. The interviewer determines the exact age of the child based on the date of birth given by the mother / caregiver and the date of the survey. The age is calculated automatically once the date of birth is entered into the tablet.

For each eligible child, two data sources are systematically used. The first is the HBR to collect vaccination status and date of vaccination. Investigators are encouraged to take pictures of HBR when they were unable to decipher vaccination dates.

The second source is the mother/caregiver statement to assess immunization status only. The questions were worded by describing the sites of administration of the vaccine, namely, the arm, shoulder, thigh and mouth in order to facilitate the understanding of mothers or caregivers.

Consultation of the HFR at the child's usual health care facility is required in one of the following situations: $i)$ the HBR is not available, ii) the HBR is available but information on vaccination is not there or not mentioned, is illegible or is incomplete. To facilitate the use of the HFR, the investigators recorded the first name, last name and date of birth of the child, as well as the first and last name of the mother before leaving the household. This information is sent, using WhatsApp, to the District Medical
Officer (DMO) who, in turn, passes it on to the head of the health facility attended by the child. The latter, once the message has been received, checks the vaccination status and the date of vaccination. This data is transmitted to the DMO again and entered into the tablets.

\section{Study variables}

Vaccination data relate to vaccination status and date of vaccination. The dependent variable was $\mathrm{HepB}-\mathrm{BD}$ vaccination coverage within $24 \mathrm{~h}$. The delay was obtained by making the difference between the date of vaccination and the date of birth. It is binary and the modalities are: yes and no. Timely vaccination is one that has taken place within $24 \mathrm{~h}$ of birth. Because the time of birth is not marked on the vaccination documents, any vaccination that took place on the day of birth or the next day is considered to have occurred within $24 \mathrm{~h}$ after birth.

The explanatory variables are those identified and organized using Andersen's theoretical model:

Predisposing variables: Mother's age ( $<20$ years old, 20-29 years old and $>30$ years old), mother's education (yes, no), marital status (married, unmarried), father's professional status (employed, unemployed), child's sex (male, female), birth order (1-2 and >2), knowledge about the age for beginning vaccination (yes, no), knowledge about the benefits of vaccination (yes, no), knowledge about co-administration (yes, no),

Enabling variables: place of residence (urban, rural), distance between residence and health facility $(<5 \mathrm{~km}, \geq 5 \mathrm{~km})$, access to newspaper (yes, no), access to radio (yes, no), access to television (yes, no), decision-making about the child's health (mother, husband/ partner, mother and partner and others), family allowance (yes, no), health insurance (yes, no), wealth quintile (poorest, poor, middle, richer, richest), availability of the HBR (yes seen, yes but not seen, no), timely initiation of BF ( $\leq 1 \mathrm{~h}$ after birth, between 1 and $24 \mathrm{~h}$ after birth, beyond $24 \mathrm{~h}$ after birth), place of delivery (health facility, outside health facility), year of birth $(2018,2019)$, season of birth (dry season, rainy season).

Need variables: ANC attendance $(<4, \geq 4)$, advice on vaccination during ANC (yes, no), Hospitalization of the newborn immediately after birth (yes, no), weighing of the newborn at birth (yes, no), gestational age (full term, prematurity), type of delivery (cesarean section, vaginal delivery), PNC attendance (yes, no, don't know), advice on vaccination during PNC (yes, no).

\section{Statistical analyzes}

In accordance with the new WHO recommendations, the inverse probability weighting method was performed for the estimation of crude vaccination coverage with BCG, OPV-zero and HepB-BD. To this end, 
the probability of including a cluster was calculated. Then, in a given cluster, the probability of including a child is estimated. The product of these two probabilities was used to obtain the probability of selecting a child knowing that the cluster is selected. The reciprocal of this probability is the weight of each child included in the sample [31].

Two types of analyzes were performed. These are descriptive statistics and analytical statistics. The descriptive part made it possible to express the variables as a proportion.

Crude vaccination coverage is calculated for each of the three birth doses. This indicator is a proportion. The numerator is the weighted number of children who received the dose. The denominator is the weighted number of children who participated in the survey.

The vaccination status of the child is treated as follows: i) if the HBR is available with complete information, then it is valid, ii) if the HBR is not available but the child was in the HFR, then this is valid or iii) if the child does not have a HBR and his name does not appear in the HFR, mother / caregiver recall about the child's vaccination history is valid.

Then, vaccination coverage within $24 \mathrm{~h}$ after birth is estimated as a proportion. For this indicator, only the HBR or the HFR are valid. The numerator is the number of children who received the vaccine within $24 \mathrm{~h}$ of life. The denominator corresponds to the number of children who received the vaccine regardless of the date of vaccination.

The analytical part consisted of investigating factors associated with timely $\mathrm{HepB}-\mathrm{BD}$ vaccination. The choice made on this dose is explained by the fact that the administration of this dose within $24 \mathrm{~h}$ after birth is an indicator of EPI performance [23]. Bivariate analysis was performed using the Chi-square test with Rao and Scott's correction. Then, the variables for which the p-value is less than or equal to 0.25 are integrated in a mixed effect multiple logistic regression model. Clusters were considered as random effect to account for the unexplained variability at the community level [33]. Variables are selected using the step-down procedure. The variance inflation factor (VIF) was examined to assess the collinearity between the explanatory variables. The significance level is set at 0.05 . All the analyzes are carried out with the $\mathrm{R}$ software.

\section{Results}

\section{Response rate}

Of the 870 children aged 12 to 23 months planned, 832 were included, for a response rate of $95.86 \%$.

\section{Basic characteristics of respondents}

More than one in two mothers or caregivers were between 20 and 29 years old, at $54.7 \%$. The proportion of married was $96.2 \%$. That of children whose fathers were employed was $94.5 \%$. Male children and those in the first or second birth order accounted for $53.0 \%$ and $45.2 \%$, respectively.

In addition, the proportion of deliveries taking place in health facilities stands at $68.8 \%$. In addition, $84.9 \%$ of mothers have attended PNC and $87.7 \%$ of children are weighed at birth (Table 1).

\section{Vaccination coverage}

Two indicators were calculated. Crude BCG, HepB-BD and OPV-zero vaccination coverage were estimated at $95.2 \%, 88.1 \%$ and $89.3 \%$, respectively. In contrast, vaccination coverage within the first $24 \mathrm{~h}$ of life was $13.9 \%$, $42.1 \%$ and $30 \%$, respectively (Table 2 ).

Factors associated with HepB-BD vaccination within $24 \mathrm{~h}$ after birth.

\section{Bivariate analysis}

In the bivariate analysis, the factors identified as associated with the administration of HepB-BD within $24 \mathrm{~h}$ after birth are: access to television, wealth quintile, institutional delivery, hospitalization of the child immediately after birth and weighing of the child at birth (Table 3). An additional file shows this in more detail [see Additional file 1].

\section{Multivariate analysis}

The multivariate analysis allowed to establish a statistically significant and independent effect of the variables named above, with the exception of the wealth quintile. Indeed, children whose mothers had access to television were 1.70 times more likely to receive HepB-BD on time ( $p$-value $=0.012)$. In addition, this chance is multiplied by $1.62(p$-value $=0.046)$ and $3.90(p$-value $<0.001)$ when the child is born in a health facility and weighed at birth, respectively. In contrast, a newborn hospitalized immediately after birth has a $58 \%$ lower chance of receiving HepB-BD on time ( $p$-value $<0.001)$ compared to an outpatient newborn (Table 4).

\section{Discussion}

This study showed that the crude vaccination coverage for BCG, OPV-zero dose and HepB-BD were 95.2\%, $89.3 \%$ and $88.1 \%$, respectively. On the other hand, vaccination coverage within $24 \mathrm{~h}$ of birth were estimated at $13.9 \%, 30 \%$ and $42.1 \%$, respectively. 
Table 1 Basic characteristics of respondents, Podor health district, June 2020 (n:unweighted $N=832, \%: W e i g h t e d ~ N=8026$ )

\begin{tabular}{|c|c|c|}
\hline Variables & $n$ & $\%$ \\
\hline \multicolumn{3}{|l|}{ Predisposing factors } \\
\hline \multicolumn{3}{|l|}{ Maternal age } \\
\hline$<20$ years & 110 & 12.6 \\
\hline 20-29 years & 439 & 54.7 \\
\hline$>30$ years & 283 & 32.6 \\
\hline \multicolumn{3}{|l|}{ Mother's education } \\
\hline Yes & 338 & 45.9 \\
\hline No & 494 & 54.1 \\
\hline \multicolumn{3}{|l|}{ Mother's marital status } \\
\hline Married & 805 & 96.2 \\
\hline Not married & 27 & 3.8 \\
\hline \multicolumn{3}{|l|}{ Profession of the child's father } \\
\hline Employment & 790 & 94.5 \\
\hline Unemployed & 42 & 5.5 \\
\hline \multicolumn{3}{|l|}{ Sex of child } \\
\hline Male & 430 & 53.0 \\
\hline Female & 420 & 47.0 \\
\hline \multicolumn{3}{|l|}{ Birth order } \\
\hline $1-2$ & 376 & 45.2 \\
\hline$>2$ & 456 & 54.8 \\
\hline \multicolumn{3}{|c|}{ Knowledge about the age for beginning vaccination } \\
\hline Yes & 643 & 80.0 \\
\hline No & 189 & 20.0 \\
\hline \multicolumn{3}{|c|}{ Knowledge about the benefits of vaccination } \\
\hline Yes & 749 & 92.6 \\
\hline No & 83 & 7.4 \\
\hline \multicolumn{3}{|c|}{ Knowledge about co-administration } \\
\hline Yes & 571 & 72.1 \\
\hline No & 261 & 27.9 \\
\hline \multicolumn{3}{|l|}{ Enabling factors } \\
\hline \multicolumn{3}{|l|}{ Place of residence } \\
\hline Urban & 202 & 27.2 \\
\hline Rural & 630 & 72.8 \\
\hline \multicolumn{3}{|l|}{ Distance } \\
\hline$<5 \mathrm{~km}$ & 534 & 70.1 \\
\hline$\geq 5 \mathrm{~km}$ & 298 & 29.9 \\
\hline \multicolumn{3}{|l|}{ Access to newspaper } \\
\hline Yes & 116 & 24.6 \\
\hline No & 716 & 75.4 \\
\hline \multicolumn{3}{|l|}{ Access to radio } \\
\hline Yes & 582 & 73.8 \\
\hline No & 250 & 26.2 \\
\hline \multicolumn{3}{|l|}{ Access to television } \\
\hline Yes & 360 & 46.9 \\
\hline No & 472 & 53.1 \\
\hline \multicolumn{3}{|l|}{ Decision-making power } \\
\hline Me/me and my husband & 802 & 97.5 \\
\hline Other & 30 & 2.5 \\
\hline
\end{tabular}

Table 1 (continued)

\begin{tabular}{|c|c|c|}
\hline Variables & $n$ & $\%$ \\
\hline \multicolumn{3}{|l|}{ Means of transport } \\
\hline On walk & 451 & 61.9 \\
\hline Transportations & 381 & 38.1 \\
\hline \multicolumn{3}{|c|}{ Beneficiary of family allowance } \\
\hline Yes & 46 & 7.7 \\
\hline No & 786 & 92.3 \\
\hline \multicolumn{3}{|c|}{ Access to health insurance } \\
\hline Yes & 41 & 5.0 \\
\hline No & 791 & 95.0 \\
\hline \multicolumn{3}{|l|}{ Quintile } \\
\hline Poorest & 166 & 22.1 \\
\hline Poor & 167 & 21.1 \\
\hline Middle & 166 & 22.7 \\
\hline Richer & 167 & 19.3 \\
\hline Richest & 166 & 14.8 \\
\hline \multicolumn{3}{|l|}{ Availability of the HBR } \\
\hline No & 35 & 3.5 \\
\hline Yes not seen & 56 & 5.3 \\
\hline Yes seen & 741 & 91.2 \\
\hline \multicolumn{3}{|l|}{ Timely initiation of BF } \\
\hline Immediately ( $\leq 1 \mathrm{~h}$ ) & 715 & 86.3 \\
\hline Beyond one hour & 117 & 13.7 \\
\hline \multicolumn{3}{|l|}{ Place of birth } \\
\hline Health facility & 574 & 68.8 \\
\hline Home & 258 & 31.2 \\
\hline \multicolumn{3}{|l|}{ Year of birth } \\
\hline 2018 & 419 & 48.7 \\
\hline 2019 & 413 & 51.3 \\
\hline \multicolumn{3}{|l|}{ Season of birth } \\
\hline Rainy season & 187 & 20.3 \\
\hline Dry season & 645 & 79.7 \\
\hline \multicolumn{3}{|l|}{ Need factors } \\
\hline \multicolumn{3}{|l|}{ Number of ANC } \\
\hline $0-3$ & 406 & 46.4 \\
\hline$\geq 4$ & 426 & 53.6 \\
\hline \multicolumn{3}{|c|}{ Advice on vaccination during ANC } \\
\hline Yes & 665 & 82.4 \\
\hline No & 167 & 17.6 \\
\hline \multicolumn{3}{|c|}{ Hospitalization of the newborn } \\
\hline Yes & 193 & 23.6 \\
\hline No & 639 & 76.4 \\
\hline \multicolumn{3}{|c|}{ Newborn weighing at birth } \\
\hline Yes & 695 & 87.7 \\
\hline No / don't know & 137 & 12.3 \\
\hline \multicolumn{3}{|l|}{ Gestational age } \\
\hline Full-term & 816 & 98.0 \\
\hline Prematurity & 16 & 2.0 \\
\hline \multicolumn{3}{|l|}{ Mode of delivery } \\
\hline Cesarean section & 82 & 12.9 \\
\hline
\end{tabular}


Table 1 (continued)

\begin{tabular}{lll}
\hline Variables & $\boldsymbol{n}$ & $\%$ \\
\hline Vaginal delivery & 750 & 87.1 \\
PNC & & \\
Yes & 677 & 84.9 \\
No / don't know & 155 & 15.1 \\
Advice during PNC & & \\
Yes & 700 & 87.2 \\
No / don't know & 132 & 12.8 \\
\hline
\end{tabular}

The factors associated with timely HepB-BD are delivery in a health facility, access to television, weighing and hospitalization of the newborn immediately after birth.

Crude vaccination coverage were higher than those observed nationally [25]. An Ethiopian study reported BCG and OPV-zero dose vaccination coverage equal to $72.9 \%$ and $18.9 \%$ according to the HBR and $77.7 \%$ and 25.1\% according to the history [34]. A recent Mongolian study found, on the basis of data extracted from the vaccination card, crude vaccination coverage reaching $97.7 \%$, 98.2\% and 98.2\% for BCG, OPV-zero dose and HepB-BD, respectively [35].

However, vaccination coverage within $24 \mathrm{~h}$ after birth is low with proportions estimated at $13.9 \%, 30 \%$ and $42.1 \%$ for BCG, OPV-zero dose and HepB-BD, respectively. Timely HepB-BD vaccination coverage is highest. Conversely, that of BCG is the weakest. Two explanations are possible. On the one hand, administration of HepB$\mathrm{BD}$ within $24 \mathrm{~h}$ after birth is a performance indicator for EPI. On the other hand, the open vial policy varies from vaccine to vaccine. The HepB-BD vaccine is contained in a ten-dose vial which can be used for a maximum of four weeks after opening if and only if the storage conditions are met [36]. On the other hand, BCG is packaged in vials of twenty doses. The vial is only opened during sessions scheduled for at least 10 to 12 children due to the inability to use the doses beyond six hours after opening the vial. In the health district of Podor, BCG administration sessions are not done daily. Therefore, children born on a day when BCG services are unavailable are very unlikely to receive BCG vaccine within $24 \mathrm{~h}$ after birth. For OPVzero dose, the schedule indicates that it can be given between the day of birth and day 14 of life. The absence of the " $24 \mathrm{~h}$ " statement may contribute to the administration of the vaccine beyond this time.

In this study, many children are not weighed or have no proof of having been weighed at birth. Thus, the study is unable to determine the impact of birth weight on the timing of vaccination. Yet, in SSA, some health professionals have erroneously stated that they do not administer HepB-BD to low birth weight, sick or premature infants [15]. This study illustrate the importance of weighing births on timely immunization. According to the CDHS-2018, only $51.8 \%$ of children were weighed at birth in the northern part of the country [37]. This may explain the fact that the absence of weighing is a barrier to vaccination at birth.

Weighing and recording the weight on health documents (HBR or HFR) are part of immediate newborn care, while administration of HepB-BD is an essential newborn care [38]. Thus, an integration of the services responsible for providing these two types of care would make it possible to increase vaccination coverage at birth.

Hospitalization of the newborn immediately after birth has rightly appeared as a barrier to timely immunization. Two Vietnamese and Italian studies published in 2008 and 2014 respectively highlighted a similar situation $[39,40]$. One explanation for this result from this current study could lie in the WHO recommendation that vaccination of newborns requiring resuscitation or other immediate care be delayed. Another explanation could be that health workers express reluctance to immunize unstable newborns, fearing that parents may falsely link adverse outcomes to the birth dose [38].

However, communication should be established between the originating and receiving institution to allow administration of the dose once the newborn is stable [38].

This study found that home birth is a barrier to immunization within $24 \mathrm{~h}$ of birth. Three studies from China, Ethiopia and Nigeria illustrate this phenomenon well

Table 2 Birth dose vaccination coverage among children aged 12 to 23 months, Podor health district (Unweighted N=832, Weighted $N=8026)$

\begin{tabular}{llllll}
\hline Birth dose vaccines & $\begin{array}{l}\text { VC according to HBR } \\
\text { (a) \% }\end{array}$ & $\begin{array}{l}\text { VC according to HBR or } \\
\text { HFR (b) \% }\end{array}$ & $\begin{array}{l}\text { VC according to history } \\
\text { (c) \% }\end{array}$ & $\begin{array}{l}\text { Crude VC (b or c) } \\
\%\end{array}$ & $\begin{array}{l}\text { VC within } \\
\mathbf{2 4} \mathbf{h} \text { of } \\
\text { life } \%\end{array}$ \\
\hline BCG & 90.1 & 91.1 & 83,4 & 95.2 & 13,9 \\
HepB-BD & 82.3 & 84.1 & 74.4 & 88.1 & 42.1 \\
OPV-zero & 83.4 & 85 & 73.5 & 89.3 & 30
\end{tabular}

VC vaccination coverage, $H B R$ home-based vaccination records, HFR Health facility register 
Table 3 Bivariate analysis of factors associated with HepB-BD vaccination coverage within 24 h, (n:unweighted N=629, \%:Weighted $N=6417$ )

\begin{tabular}{|c|c|c|c|}
\hline \multirow[t]{2}{*}{ Variables } & \multicolumn{2}{|c|}{ HepB-BD vaccination coverage within $24 \mathrm{~h}$} & \multirow[t]{2}{*}{$p$-value } \\
\hline & Yes $n(\%)$ & No $n(\%)$ & \\
\hline \multicolumn{4}{|l|}{ Predisposing factors } \\
\hline Child's mother's age (years) & & & 0.894 \\
\hline$<20$ & $38(44.3 \%)$ & $52(55.7 \%)$ & \\
\hline $20-29$ & 135 (40.7\%) & $191(59.3 \%)$ & \\
\hline$>30$ & $92(42.1 \%)$ & $121(57.9 \%)$ & \\
\hline Mother's education & & & 0.503 \\
\hline No & 137 (39.9\%) & $215(60.1 \%)$ & \\
\hline Yes & $128(43.5 \%)$ & $149(56.5 \%)$ & \\
\hline Marital status & & & 0.817 \\
\hline Unmarried & $8(38.0 \%)$ & $15(62.0 \%)$ & \\
\hline Married & $257(41.7 \%)$ & $349(58.3 \%)$ & \\
\hline Profession of the child's father & & & 0.703 \\
\hline Employment & $254(41.8 \%)$ & $344(58.2 \%)$ & \\
\hline Unemployed & $11(37.5 \%)$ & $20(62.5 \%)$ & \\
\hline Sex of child & & & 0.102 \\
\hline Female & $118(37.0 \%)$ & $183(63.0 \%)$ & \\
\hline Male & 147 (45.6\%) & $181(54.4 \%)$ & \\
\hline Birth order & & & 0.474 \\
\hline$>2$ & 140 (39.9\%) & $203(60.1 \%)$ & \\
\hline $1-2$ & $125(43.7 \%)$ & $161(56.3 \%)$ & \\
\hline Knowledge about the age for beginning vaccination & & & 0.741 \\
\hline No & $51(39.9 \%)$ & $72(60.1 \%)$ & \\
\hline Yes & $214(41.9 \%)$ & $292(58.1 \%)$ & \\
\hline Knowledge about the benefits of vaccination & & & 0.126 \\
\hline No & $26(53.4 \%)$ & $27(46.6 \%)$ & \\
\hline Yes & $239(40.8 \%)$ & $337(59.2 \%)$ & \\
\hline Knowledge about co-administration & & & 0.869 \\
\hline No & $70(42.3 \%)$ & $98(57.7 \%)$ & \\
\hline Yes & 195 (41.4\%) & $266(58.6 \%)$ & \\
\hline \multicolumn{4}{|l|}{ Enabling factors } \\
\hline Place of residence & & & 0.834 \\
\hline Rural & $185(41.2 \%)$ & $275(58.8 \%)$ & \\
\hline Urban & $80(42.5 \%)$ & $89(57.5 \%)$ & \\
\hline Distance between home and health facility & & & 0.214 \\
\hline$\geq 5 \mathrm{~km}$ & $83(46.6 \%)$ & 115 (53.4\%) & \\
\hline$<5 \mathrm{~km}$ & 182 (39.9\%) & $249(60.1 \%)$ & \\
\hline Access to newspaper & & & 0.044 \\
\hline No & $224(45.3 \%)$ & $308(54.7 \%)$ & \\
\hline Yes & $41(31.9 \%)$ & $56(68.1 \%)$ & \\
\hline Acces to Radio & & & 0.014 \\
\hline No & $70(31.1 \%)$ & 105 (68.9\%) & \\
\hline Yes & 195 (45.1\%) & 259 (54.9\%) & \\
\hline Access to television & & & 0.017 \\
\hline No & $114(35.4 \%)$ & $220(64.6 \%)$ & \\
\hline Yes & $151(48.0 \%)$ & $144(52.0 \%)$ & \\
\hline
\end{tabular}


Table 4 Factors associated with HepB-BD vaccination coverage within 24 h, Podor health district, June 2020

\begin{tabular}{|c|c|c|c|}
\hline Variables & OR $_{\text {adjusted }}$ & $95 \% \mathrm{Cl}$ & $P$-value \\
\hline \multicolumn{4}{|l|}{ Child's sex } \\
\hline Male & 1.32 & $0,92-1.91$ & 0.133 \\
\hline Female & 1 & & \\
\hline \multicolumn{4}{|l|}{ Access to television } \\
\hline Yes & 1.70 & $1.12-2.57$ & 0.012 \\
\hline No & 1 & & \\
\hline \multicolumn{4}{|l|}{ Place of birth } \\
\hline Health facility & 1.62 & $1.04-2.67$ & 0.046 \\
\hline Home & 1 & & \\
\hline \multicolumn{4}{|c|}{ Hospitalization of newborn immediately after birth } \\
\hline Yes & 0.42 & $0.26-0.68$ & $<0.001$ \\
\hline No & 1 & & \\
\hline \multicolumn{4}{|c|}{ Newborn weighing immediately at birth } \\
\hline Yes & 3.90 & $1.79-8.53$ & $<0.001$ \\
\hline No / don't know & 1 & & \\
\hline
\end{tabular}

[41-43], regardless of the socio-economic conditions of the mothers [42]. There is evidence that women who give birth in health facilities are those who live near them [41]. However, the health district of Podor is marked by its quasi-rural character and a large part of its population is located more than $5 \mathrm{~km}$ from health facilities [29]. The lack of mobile logistics can also hamper the holding of vaccination sessions in advanced or mobile strategy. This situation is the bedrock of the recurrence of home births, and consequently of the delay or absence of the administration of the vaccination from birth. In this regard, il would be to reach children born outside health facilities [44]. Success factors for immunizing children born at home are documented by WHO. These include the holding of home visits to provide the vaccine or other postnatal care, the monitoring of pregnancies at the community level by community health workers (CHWs) and the storage out-of-cold-chain (OCC) of vaccines but under controlled temperature chain (CTC) [44]. A study carried out in the Republic of Kiribati has shown that the identification, census and reporting of pregnant women or women in labor phase by the CHWs greatly improve vaccination coverage at birth among children born at home [45].

Additionally, the study found that access to television was positively associated with administration of HepB-BD within $24 \mathrm{~h}$ of birth. This result is evocative of the importance of the educational role of the media in public health. More and more people are interested in issues related to their health. Thus, the media are seen as a powerful channel for disseminating information and increasing vaccine awareness and the opinions of vaccine supporters and opponents [46]. This result is a reminder of the need for each country that has introduced HepB$\mathrm{BD}$ in its EPI to put in place a general response plan against adverse events following immunization (AEFI), anti-vaccine movements, and any allegation likely to be harmful public acceptance of HepB-BD and confidence in the EPI [38]. This is all the more necessary as the rapid growth of the Internet and social networks have made it easier to research and disseminate concerns and misperceptions related to immunization [46]. For example, in Vietnam, it was observed a decrease in vaccination coverage with HepB-BD after media reports of AEFI that occurred following HepB-BD administration [47].

\section{Strengths and weaknesses}

The strengths of this study are important to underline. First, the sample size and number of clusters were calculated according to the new WHO recommendations for immunization coverage surveys [31].

Cross-sectional studies are subject to selection and information bias, as well as to confounding factors [48]. In this present study, the circumstance likely to introduce selection bias is related to non-response. However, the use of weighting made it possible to control the bias. This is demonstrated in the literature $[49,50]$.

Then, the introduction of information bias is mitigated by three strategies. The first is the use of HFR when HBR is unavailable or does not provide accurate immunization status information. The second strategy is to choose a cohort of children aged 12 to 23 months, thus allowing mothers or caregivers to remember the vaccines received. Finally, the training of interviewers and the pretest of the questionnaire made it possible to harmonize the data collection procedures. Kesmodel US considers that this method is one of the rare solutions to control this type of bias [51].

Confounding factors are a major source of bias [52]. In this study, socio-economic factors may emerge as confounding factors in the link between delivery in a health facility and timely vaccination. The effect of such confusion was controlled through the use of logistic regression. This demonstrated the stability of the link between childbirth in a health facility and the administration of the birth dose within $24 \mathrm{~h}$ of birth; whatever the socioeconomic level.

This study has three main limitations. The first is due to its cross sectional nature, which does not allow a causal relationship to be established between the independent variables and the dependent variable. The second limitation relates to the geographic nature of the study. This was conducted in a single district which may have different characteristics compared to other health districts in the country. Therefore, the generalizability of the results should be viewed with caution. The third 
limitation is that the time of birth is not mentioned in the HFR. In this case, it is difficult to know precisely whether the child is vaccinated or not within $24 \mathrm{~h}$ of birth. The resulting consequence would be the overestimation of immunization coverage within $24 \mathrm{~h}$ of birth.

\section{Conclusion}

This study indicated satisfactory crude vaccination coverage. But those for the $24-\mathrm{h}$ postnatal period are very low. Factors favorable to timely vaccination were access to television, delivery in a health facility and weighing the newborn immediately after birth. In contrast, hospitalization of the newborn immediately after birth was found to be a barrier. Therefore, actions should focus on sensitizing mothers on the importance of immunization at birth using mass media such as television, conducting home visits and pregnancy monitoring by CHWs to administer timely birth doses to homeborn children, integrating immunization at birth with essential neonatal care such as weighing, and creating linkages between neonatal immunization services and hospitalization services.

In addition, further studies should be conducted to increase knowledge about the facets of birth vaccination.

\begin{abstract}
Abbreviations
AEFl: Adverse event following immunization; ANC: Antenatal care; AOR: Adjusted odds ratio; BCG: Bacille Calmette et Guérin; BF: Breastfeeding; CDHS: Continuous Demographic and Health Survey; CHW: Community health workers; CTC: Controlled temperature chain; EPI: Expanded programme on imminuzation; HBR: Home-based record; HBV: Hepatitis B virus; Hep-BD: Birth dose of hepatitis B vaccine; HFR: Health facility registry; OCC: Out-of-coldchain; OPV-zero: Birth dose of oral polio vaccine; PNC: Postnatal care; SSA: SubSaharan Africa; VIF: Variance inflation factor; WHO: World Health Organization.
\end{abstract}

\section{Supplementary Information}

The online version contains supplementary material available at https://doi. org/10.1186/s12889-022-12535-z.

Additional file 1: Table 3. Bivariate analysis of factors associated with HepB-BD vaccination coverage within 24 hours $(N=629)$, continued. Table 3. Bivariate analysis of factors associated with $\mathrm{HepB}-\mathrm{BD}$ vaccination coverage within 24 hours $(N=629)$, continued and end.

\section{Acknowledgements}

We would like to thank all the mothers and caregivers who participated in this study, as well as the village chiefs and health care providers in the Podor health district who facilitated data collection.

\section{Authors' contributions}

Bassoum O: Concept and design of study, analysis and interpretation of data; Drafting the article. Ba MF: analysis of data. All authors: revising the critically for important intellectual content; Final approval of the version to be published.

\section{Funding}

Not applicable.

\section{Availability of data and materials}

The data used to conduct this study is available from the corresponding author.

\section{Declarations}

\section{Ethics approval and consent to participate}

The study obtained ethical approval from the 'Comité d'Ethique de la Recherche' (CER) of Cheikh Anta Diop University, Dakar, Senegal (reference 0253/2017 / CER / UCAD). This study was conducted according to the guidelines laid down in the Declaration of Helsinki. An informed consent from the participants, mother or caregiver was obtained for the present study. The participant was informed of the right to refuse to participate in the study or to withdraw her consent to participate at any time, without justification. The data was collected anonymously and confidentially.

\section{Consent for publication}

Not applicable.

\section{Competing interests}

The authors declare that they have no competing interests.

\section{Author details}

'Service de Médecine Préventive Et de Santé Publique, Faculté de Médecine, de Pharmacie Et d'Odontologie (FMPO), Université Cheikh Anta Diop (UCAD), Dakar, Sénégal. ${ }^{2}$ Institut de Santé Et Développement, Université Cheikh Anta Diop, Dakar, Sénégal. ${ }^{3}$ Ministère de La Santé Et de L'Action Sociale, Dakar, Sénégal. ${ }^{4}$ Service d'Immunologie, FMPO, UCAD, Dakar, Sénégal. ${ }^{5}$ Institut de Recherche Pour Le Développement, Campus UCAD/IRD de Hann, Dakar, Sénégal. ${ }^{6}$ Institut Hospitalo-Universitaire - Méditerranée Infection, Marseille, France.

Received: 26 March 2021 Accepted: 4 January 2022

Published online: 15 January 2022

\section{References}

1. IG-GP Vanhems 2015 Vaccinations Collège Universitaire des Enseignants de Santé Publique (CUESP) Sante Publique. 3 ème éd. Issy- les-Moulineaux: Elsevier Masson SAS; . p. 304-15.

2. Greenwood B. The contribution of vaccination to global health: Past, present and future. Philos Trans R Soc B Biol Sci. 2014;369(1645):1-9.

3. Canouï E, Launay O. Histoire et principes de la vaccination. Rev Mal Respir. 2019:36(1):74-81.

4. Organisation Mondiale de la Santé. Vaccins BCG: Note de synthèse de I'OMS - Février 2018. Relev épidémiologique Hebd. 2018;8(93):73-96 (http://www.who.int/immunization/sage/).

5. Organisation Mondiale de la Santé. Note de synthèse de l'OMS sur les vaccins antipoliomyélitiques - mars 2016. Relev épidémiologique Hebd. 2016:91(12):145-68.

6. Organisation Mondiale de la Santé. Vaccins anti-hépatite B: note de synthèse de l'OMS - juillet 2017. Relev épidémiologique Hebd. 2017:92(27):369-92

7. World Health Organization. Global tuberculosis report 2020. Geneva: WHO; 2020. (https://apps.who.int/iris/bitstream/handle/10665/336069/ 9789240013131-eng.pdf?ua=1 cited 2020 Oct 30).

8. World Health Organization. Global hepatitis report 2017. Geneva: WHO; 2017. (https://apps.who.int/iris/bitstream/handle/10665/255016/97892 41565455-eng.pdf? sequence $=1$ cited 2020 Sep 3).

9. Razavi-Shearer D, Gamkrelidze I, Nguyen MH, Chen D-S, Van Damme P, Abbas Z, et al. Global prevalence, treatment, and prevention of hepatitis $B$ virus infection in 2016: a modelling study. Lancet Gastroenterol Hepatol. 2018;3(6):383-403. https://doi.org/10.1016/S2468-1253(18)30056-6.

10. World Health Organization. The beginning of the end. Geneva: WHO; 1997. (http://www.who.ch/programmes/gpv/gpv_home.htmcited 2020 Sep 4).

11. Organisation Mondiale de la Santé. L'Initiative mondiale pour l'éradication de la poliomyélite félicite la région africaine de l'OMS certifiée exempte de poliomyélite sauvage. Genève: OMS; 2020. (https:// www.who.int/fr/news/item/25-08-2020-global-polio-eradication-initi 
ative-applauds-who-african-region-for-wild-polio-free-certificationcited 2020 Dec 8).

12. Organisation Mondiale de la Santé. Stratégie finale d'éradication de la poliomyélite 2019-2023: Éradication, intégration, certification et confinement. Genève: OMS; 2019. (http://polioeradication.org/wp-conte nt/uploads/2019/06/french-polio-endgame-strategy.pdfcited 2020 Nov 2).

13. Weckx LY, Schmidt BJ, Herrmann AA, Miyasaki CH, Novo NF. Early immunization of neonates with trivalent oral poliovirus vaccine. Bull World Health Organ. 1992;70(1):85-91 (https://pubmed.ncbi.nlm.nih. gov/1314711).

14. Bassoum O, Kimura M, Dia AT, Lemoine M, Shimakawa Y. Coverage and timeliness of birth dose vaccination in sub-Saharan Africa: A systematic review and meta-analysis. Vaccines. 2020;8(2):1-16 (https://www. embase.com/search/results?subaction=viewrecord\&id $=$ L200457210 5\&from=export).

15. Moturi E, Tevi-Benissan C, Hagan JE, Shendale S, Mayenga D, Murokora D, et al. Implementing a Birth Dose of Hepatitis B Vaccine in Africa: Findings from Assessments in 5 Countries. J Immunol Sci. 2018;Suppl(5):31-40.

16. Al-Jayyousi GF, Sherbash MAM, Ali LAM, El-Heneidy A, Alhussaini NWZ, Elhassan MEA, et al. Factors Influencing Public Attitudes towards COVID-19 Vaccination: A Scoping Review Informed by the Socio-Ecological Model. Vaccines. 2021;9(6):548 (https://pubmed.ncbi.nlm.nih. gov/34073757).

17. Soares P, Rocha JV, Moniz M, Gama A, Laires PA, Pedro AR, et al. Factors Associated with COVID-19 Vaccine Hesitancy. Vaccines. 2021;9(3):300 (https://pubmed.ncbi.nlm.nih.gov/33810131).

18. MacDonald NE. Vaccine hesitancy: Definition, scope and determinants. Vaccine. 2015;33(34):4161-4.

19. World Health Organization. Tuberculosis profile: Senegal. Geneva: WHO; 2020. (https://worldhealthorg.shinyapps.io/tb_profiles/?_inputs_ \&entity_type $=\% 22$ country $\% 22 \& l a n=\% 22$ EN $\% 22 \& i s O 2=\% 22$ SN\% 22cited 2020 Dec 8).

20. Schillie S, Vellozzi C, Reingold A, Harris A, Haber P, Ward JW, et al. Prevention of Hepatitis B Virus Infection in the United States: Recommendations of the Advisory Committee on Immunization Practices. MMWR Recomm reports Morb Mortal Wkly report Recomm reports. 2018;67(1):1-31 (https://pubmed.ncbi.nlm.nih.gov/29939980).

21. Diop M, Diouf A, Seck SM, Lo G, Ka D, Massaly A, et al. Prévalence de l'antigène de surface du virus de l'hépatite $B$ et facteurs associés chez des militaires sénégalais envoyés en mission au Darfour. Pan Afr Med J. 2017; 15(26):154.

22 Schweitzer A, Horn J, Mikolajczyk RT, Krause G, Ott JJ. Estimations of worldwide prevalence of chronic hepatitis B virus infection: a systematic review of data published between 1965 and 2013. Lancet. 2015;386(10003):1546-55. https://doi.org/10.1016/S0140-6736(15) 61412-X.

23 Ministère de la Santé et de l'Action Sociale. Guide de gestion du programme élargi de vaccination etde la surveillance épidémiologique. Dakar: MSAS; 2017

24. Spearman CW, Afihene M, Ally R, Apica B, Awuku Y, Cunha L, et al. Hepatitis B in sub-Saharan Africa: strategies to achieve the 2030 elimination targets. The Lancet Gastroenterology and Hepatology. 2017. p. 900-9.

25. Agence Nationale de la Statistique et de la Démographie. Enquête Démographique et de Santé Continue (EDS- Continue) 2019. Dakar: ANSD/ICF; 2020. p. 208 (https://www.dhsprogram.com/pubs/pdf/ FR368/FR368.pdf).

26. Systeme d'information sanitaire / MSAS [Internet]. [cited 2019 Aug 28]. Available from: https://senegal.dhis2.org/dhis/dhis-web-commons/ security/login.action

27. Organization PAH. Tools for monitoring the coverage of integrated public health interventions. Washington, D.C.: PAHO; 2017.

28. Andersen RM. Revisiting the behavioral model and access to medical care: does it matter? J Health Soc Behav. 1995:36(1):1-10.

29 District sanitaire de Podor. Engagement communautaire-Comité de vigilance et de sensibilisation: Riposte contre la COVID-19. Podor: MSAS; 2020.

30. Agence Nationale de la Statistique et de la Démographie. Situation économique et sociale régionale 2017-2018. Dakar: ANSD; 2020.
(http://www.ansd.sn/ressources/ses/SES-Saint-Louis-2017-2018.pdfcited 2020 Dec 3).

31. Organisation Mondiale de la Santé. Enquêtes de couverture vaccinales par sondage en grappes : Manuel de référence. Genève: Suisse; 2015. (https://www.who.int/immunization/monitoring_surveillance/Vacci nation_coverage_cluster_survey_FR.pdf?ua=1 cited 2020 Sep 25).

32. Agence Nationale de la Statistique et de la Démographie. Enquête Démographique et de Santé Continue (EDS-Continue) 2017. Dakar: ANSD; 2018. p. 646 (http://dhsprogram.com/pubs/pdf/FR345/FR345. pdfcited 2020 Jan 7).

33. Seidu A-A. Mixed effects analysis of factors associated with barriers to accessing healthcare among women in sub-Saharan Africa: Insights from demographic and health surveys. PLoS One. 2020;15(11):e0241409.

34. Tesfaye TD, Temesgen WA, Kasa AS. Vaccination coverage and associated factors among children aged 12-23 months in Northwest Ethiopia. Hum Vaccin Immunother. 2018;14(10):2348-54.

35. Rauniyar SK, Munkhbat E, Ueda P, Yoneoka D, Shibuya K, Nomura S. Timeliness of routine vaccination among children and determinants associated with age-appropriate vaccination in Mongolia. Heliyon. 2020;6(9):e04898-e04898 (https://pubmed.ncbi.nlm.nih.gov/32995 607).

36. Ministère de la Santé et de I'Action Sociale. Introduction du vaccin contre l'hépatite B à la naissance au Sénégal: Manuel de formation. Dakar: MSAS; p. 43.

37. Agence Nationale de la Statistique et de la Démographie. Enquête Démographique et de Santé Continue (EDS- Continue) 2018. Dakar: ANSD; 2020. p. 454 (https://www.dhsprogram.com/pubs/pdf/FR367/ FR367.pdfcited 2021 Feb 7).

38. Organisation Mondiale de la Santé. Prévenir la transmission périnatale du virus de l'hépatite B : Guide pour l'introduction et le renforcement de la vaccination à la naissance contre l'hépatite B. Genève: OMS; 2016. (http://www.who.int/about/licensing/copyright_form/en/index. htmlcited 2020 Oct 7).

39. Murakami H, Van Cuong N, Huynh L, Hipgrave DB. Implementation of and costs associated with providing a birth-dose of hepatitis B vaccine in Viet Nam. Vaccine. 2008;26(11):1411-9 (https://app.dimensions.ai/ details/publication/pub.1010903952).

40. Tozzi AE, Piga S, Corchia C, Di Lallo D, Carnielli V, Chiandotto V, et al. Timeliness of routine immunization in a population-based Italian cohort of very preterm infants: results of the ACTION follow-up project. Vaccine. 2014;32(7):793-9.

41 Hu Y, Chen Y, Wang Y, Liang H. Hepatitis B vaccination among 19992017 birth cohorts in Zhejiang Province: the determinants associated with infant coverage. Int J Environ Res Public Health. 2018;15(12):2915.

42 Boulton ML, Carlson BF, Wagner AL, Porth JM, Gebremeskel B, Abeje Y. Vaccination timeliness among newborns and infants in Ethiopia. PLoS One. 2019;14(2):e0212408.

43. Ibraheem R, Abdulkadir M, Akintola M, Adeboye M. Determinants of Timely Presentation for Birth Dose Vaccination at an Immunization Centre in North-central Nigeria. Ann Glob Heal. 2019;85(1):20.

44. Organisation mondiale de la santé. Les pratiques qui améliorent la couverture par la vaccination anti-hépatite $B$ à la naissance. Genève: OMS; 2014. (https://apps.who.int/iris/bitstream/handle/10665/112532/ WHO_IVB_12.11_fre.pdf;jsessionid=D4A770E870420A32F504A23DF CDOE992? sequence $=1$ cited $2019 \mathrm{Sep} 12$ ).

45. Li X, Heffelfinger J, Wiesen E, Diorditsa S, Valiakolleri J, Nikuata AB, et al. Improving hepatitis B birth dose coverage through village health volunteer training and pregnant women education. Vaccine. 2017:35(34):4396-401.

46. Catalan-Matamoros D, Peñafiel-Saiz C. Exploring the relationship between newspaper coverage of vaccines and childhood vaccination rates in Spain. Hum Vaccines Immunother. 2020;16(5):1055-61.

47. Li X, Wiesen E, Diorditsa S, Toda K, Duong TH, Nguyen LH, et al. Impact of Adverse Events Following Immunization in Viet Nam in 2013 on chronic hepatitis B infection. Vaccine. 2016;34(6):869-73.

48. Kesmodel US. Cross-sectional studies - what are they good for? Acta Obstet Gynecol Scand. 2018;97(4):388-93.

49. Nohr EA, Liew Z. How to investigate and adjust for selection bias in cohort studies. Acta Obstet Gynecol Scand. 2018;97(4):407-16. 
50. Giraldo A, Dalla ZG. Une procédure de redressement du biais de non-réponse : le cas de l'enquête italienne sur la fécondité urbaine, 2001-2002. Population (Paris). 2006;61(3):331-44.

51. Kesmodel US. Information bias in epidemiological studies with a special focus on obstetrics and gynecology. Acta Obstet Gynecol Scand. 2018;97(4):417-23.

52. Howards PP. An overview of confounding. Part 1: the concept and how to address it. Acta Obstet Gynecol Scand. 2018;97(4):394-9.

\section{Publisher's Note}

Springer Nature remains neutral with regard to jurisdictional claims in pub-

lished maps and institutional affiliations.

Ready to submit your research? Choose BMC and benefit from:

- fast, convenient online submission

- thorough peer review by experienced researchers in your field

- rapid publication on acceptance

- support for research data, including large and complex data types

- gold Open Access which fosters wider collaboration and increased citations

- maximum visibility for your research: over $100 \mathrm{M}$ website views per year

At $B M C$, research is always in progress.

Learn more biomedcentral.com/submissions 